\title{
ÉTICA E PSICOLOGIA CONSIDERAÇÕES SOBRE A PESSOA NA PSICOTERAPIA
}

\author{
José Mauricio de Carvalho*
}

\begin{abstract}
RESUMO
Neste trabalho, vamos apresentar as interdições éticas aos procedimentos psicoterápicos. Nossa reflexão vai se concentrar sobre a psicoterapia individual e terá por referencial teórico as contribuições da fenomenologia para a compreensão da existência humana.
\end{abstract}

Palavras-chave: Psicoterapia. Ética. Fenomenologia.

\section{RÉSUMÉ}

Nous présenterons dans ce travail les interdictions éthiques aux procédures psychotherapiques. Notre reflexion s'appuiera sur la psychotherapie individuel et aura comme référent théorique les contributions de la phénoménologie pour la compréhension de l'existence humaine.

Mots clés: Psychothérapie. Éthique. Phénoménologie.

\section{Considerações iniciais}

A pessoa humana tornou-se o principal valor de nossa cultura.

* Professor Adjunto do Departamento das Filosofias e Métodos da Universidade Federal de São João del Rei. 
Admiti-lo leva a avaliar todas as relações estabelecidas no espaço social. Neste trabalho vamos examinar a importância do ideal de pessoa presidir as relações psicoterapêuticas.

O que é a psicoterapia? Não é propriamente uma técnica psiquiátrica que estuda os distúrbios do funcionamento mental de maneira específica, conforme destaca Cunha (1978): "procurando as causas físicas dos distúrbios mentais e as tratando como às de qualquer outra doença" (p. 162). A psicoterapia, segundo Henri Piéron (1975), é "o conjunto das técnicas que visam o tratamento das moléstias mentais por meios de procedimentos psíquicos" (p. 354). Hoje já não falamos propriamente de moléstias mentais, mas o que o conceito identifica o essencial. Os procedimentos podem ser aplicados nos indivíduos ou grupos. Concentramos nosso exame no que afeta os indivíduos. Sabemos que mesmo sem certezas inquestionáveis, como dizia Freud: "nenhum mal pode ser temido para o paciente, se o tratamento é conduzido com real compreensão" (Cunha, 1978. p. 159).

Uma das características da reflexão ética em nossos dias é voltar-se para assuntos específicos, recortes da vida coletiva. Como já dissemos (2004): "a aplicação da ética a questões setoriais é uma das marcas de nosso tempo, em que pese já ser feita há muito tempo" (p. 12). Na relação entre a ética e a psicoterapia, as interdições que se aplicam no tratamento dos indivíduos afetam também as pessoas quando são tratadas em grupo. Contudo, algumas singularidades diferenciam os dois procedimentos e é necessário precisar que vamos examinar as interdições éticas à psicoterapia individual.

\section{O ideal de pessoa humana}

Entendo que não se pode falar de ética na psicoterapia sem notar que os princípios que a regulamentam nascem dentro da sociedade. É a sociedade que formula os ideais éticos que, espera, guiem a conduta de seus membros. Pode ocorrer que algumas gerações diminuam a preocupação com os princípios éticos que tomam por ideal e isto é preocupante. Contudo, na história do Ocidente, este ideal está preservado desde que foi elaborado.

Educ. e Filos., Uberlândia, v. 20, n. 39, p. 131-146, jan./jun. 2006. 
Miguel Reale elabora considerações preciosas sobre a condição humana que vamos tomar como justificativa da dignidade da pessoa. Como todos os filósofos do seu tempo, Reale considera que o homem é um ser circunstanciado. Isto significa que o homem vive uma realidade temporal. A historicidade do homem inclui de modo inseparável o passado, o presente e o futuro. $\mathrm{O}$ existente recebe influência de seu meio, mas constrói o seu futuro, objetivando valores, isto é, colocando no mundo um pouco do que ele próprio é. Fazendo-o, altera a circunstância em que vive e se modifica também. Como compreender a doutrina realiana do homem e este seguimento axiológico? Através do ideal de pessoa, nascido, como em Max Scheler (1874-1928), a partir da pergunta: que é o homem? Essa indagação tem implicação moral, resumida por Reale em duas assertivas (1987): "o ser do homem é o seu dever ser, a pessoa é o valor fonte de todos os valores" (p. 251). Como esses aspectos se relacionam? O filósofo explica que aquilo que unifica todas as ciências normativas deve ser buscado no próprio homem, não como entidade abstrata, mas como sujeito social orientado em sua vida coletiva por objetivos superiores. É em seu meio cultural que o dever ser de cada homem se manifesta como valor fonte de todos os outros valores. É o homem o maior valor da nossa cultura e é por causa dele que as outras coisas adquirem importância.

O que há de extraordinário no homem é o fato de ele estar em permanente fazer-se no exercício de sua liberdade. Durante toda sua vida, ele busca um sentido. Pensar e apor sentido à própria vida significa que o homem vive entre o que experimenta concretamente e o ideal que com todos os outros concebe. A capacidade do homem de transcender-se para realizar este ideal encontra limite na sua historicidade, mas é um valor infinito na medida em que permite ou é condição para todas as relações sociais, conforme explica Reale (1989):

O indivíduo se transcende e põe-se perante outros indivíduos, os quais, por sua vez, transcende, surge uma relação entre um eu e outro que converte o indivíduo em

Educ. e Filos., Uberlândia, v. 20, n. 39, p. 131-146, jan./jun. 2006. 
pessoa, isto só possível na medida em que o meu dever ser se concilia com o dever ser de outrem (p. 251).

É preciso ainda esclarecer como a dignidade do homem tem atualmente reconhecimento universal. Como esclarece Paim (2003): "Pode-se dizer que o núcleo da moral no ocidente é o ideal de pessoa humana" (p. 92). Esse ideal permaneceu intacto desde que foi formulado, apenas ganhou melhor compreensão. Esse valor, uma vez reconhecido, passa a integrar a condição do existente, constitui o que Miguel Reale chamou de invariante ou constante axiológico e fundamenta todas as relações que os homens estabelecem na cultura, inclusive a psicoterapia. Conforme já explicamos (1998):

Os elementos que formam o núcleo moral são a base sobre a qual as regras de negociação e o exercício contínuo de viver eticamente as situações concretas do dia a dia se concretizam. $\mathrm{O}$ reconhecimento da dignidade humana representa o que hoje conseguimos traduzir como direito à vida, à liberdade, à igualdade perante as normas jurídicas, à salvaguarda contra castigos violentos e aviltantes (p. 110).

Se reconhecemos que o homem é o principal valor de nossa cultura, ele deve ser, tratado com absoluto respeito nas diferentes relações sociais. Dito de forma simples: "atitudes éticas são aquelas que não vão prejudicar outras pessoas" (Souza, 2002. p. 101). Contudo, só isto não basta. É preciso reconhecer a humanidade em mim e no outro sempre como um fim, nunca como um meio, segundo fórmula consagrada por Kant. A psicoterapia não foge a esta exigência e é sobre isto que falaremos a seguir. Como respeitar a dignidade da pessoa reconhecida imprescindível em nosso tempo como base de uma vida autenticamente humana.

\section{O compromisso do psicoterapeuta consigo próprio}

O respeito pelo ideal de pessoa humana começa pelo respeito do terapeuta consigo próprio, com a responsabilidade de sua

Educ. e Filos., Uberlândia, v. 20, n. 39, p. 131-146, jan./jun. 2006. 
formação. Ele não pode iniciar o tratamento de ninguém sem que se sinta em condição de fazê-lo e deve inevitavelmente começar sob acompanhamento de seus formadores. O cuidado e atenção com os estágios onde se pratica psicoterapia é necessário porque é neles que o estudante começa a atividade profissional com a segurança necessária para realizar a difícil tarefa de tratar a alma humana. Esta não é uma atividade que ele possa começar sozinho e sem acompanhamento.

Ao iniciar seu trabalho e se voltar para as dores alheias, o terapeuta não pode menosprezar as suas dores; aquele que auxilia, muitas vezes, necessita de ajuda. Há casos em que o psicoterapeuta deve mesmo passar pelo processo, embora não seja esta uma condição para ele se tornar psicólogo. Como notam Henri Ey e outros (1978), um psicoterapeuta necessita preservar "um suficiente equilíbrio para que sua saúde física e mental suporte os seus problemas pessoais" (p. 49). Há, portanto, um compromisso ético com o próprio equilíbrio porque sua estabilidade emocional e intelectual afetam as relações de ajuda que estabelecerá.

Há muitos motivos para alguém tornar-se psicoterapeuta. Quaisquer que sejam estas razões, uma vez feita a escolha, do início do processo de formação até o fim da vida profissional, o psicoterapeuta há de se comprometer com a investigação da alma humana. Ele precisará estudar. Tudo que o ajude a entender melhor o universo interior do homem precisa estar em sua lista de prioridades, completando sua formação escolar. As questões filosóficas sobre o homem são muito importantes e necessitam ser meditadas. Há também romances para ler, pinturas para serem contempladas, esculturas para se admirar, representações teatrais e filmes para visitar e assistir, enfim, o universo humano se dá a conhecer de tantas formas. Nenhuma delas pode ficar fora do interesse do psicoterapeuta.

\section{Os riscos existenciais e a psicoterapia}

Filósofos e psicólogos entendem que o homem é um ser que busca a auto-realização, isto é, que vai atrás de um bem-estar 
íntimo que chamamos felicidade. Difícil precisarmos em que consiste tal felicidade, mas podemos ficar com o que disse Inêz Lemos (2004):

Felicidade pode ser isso, conseguir viver cada vez mais perto do próprio desejo. Tentar o que ainda não foi tentado, desvendando outras formas de viver. Uma felicidade tranqüila, onde predomina a calma de quem quer encontrar, e não apenas buscar. Quanto mais de nós colocamos na esperança de conquistar algo que desejamos, mais ampliamos a chance disso acontecer (p. 3).

O homem não dispõe de tempo longo para realizar tal projeto, seu tempo "é limitado por um pequeno número de dias e horas e não podemos nos dar ao luxo de utilizar mal esse tempo" (Carvalho, 2002. p. 61). Devemos esclarecer que felicidade é coisa distinta de prazer e impossível de ser estabelecida como programa único para todas as pessoas. Cada homem é responsável por sua felicidade por encontrar os caminhos que levem a sua realização, ou conforme diz Inêz Lemos (2003): “o homem se implicando em suas condições sociais e existenciais de vida" (p. 3) busca realizar-se em meio a riscos. A razão disto, nos esclarece Roger Garaudy (1966): “é que o homem, cuja liberdade é ao mesmo tempo sustentada e ameaçada pelo mundo e pela transcendência, nasceu sem justificação: está aí" (p. 56).

Nossa sociedade dos remédios possantes e drogas sofisticadas difundiu a ilusão de que se possa viver sem riscos e dor. Os meios de comunicação usam mensagens subliminares para iludir que se compra e se vende a felicidade do mesmo modo que se adquire qualquer objeto. Esta sociedade ensina que ser feliz é possuir bens, estimula esta idéia fantasiosa da felicidade, favorecendo, assim, a expressão de impulsos primitivos e narcisistas, ordinariamente irreais e não realizáveis.

A psicoterapia não pode entrar neste falso esquema e se apresentar como panacéia, isto é, conjunto de procedimentos que produzem a falsa imagem de mudança pessoal sem desejo e

Educ. e Filos., Uberlândia, v. 20, n. 39, p. 131-146, jan./jun. 2006. 
empenho. Ela não pode ser apresentada como técnica de ajuda para uma geração que aprendeu a tratar suas angústias e dúvidas existenciais com drogas sofisticadas porque a realidade é bem outra: "o homem é chamado a fazer-se, a construir a própria existência, pois existir significa estar aí, marcar presença no mundo, na contingência e na temporalidade histórica" (Espínola, 1998. p. 18). Para levar adiante semelhante tarefa, ele não pode contar com as drogas e nem está a salvo de sofrimentos e desilusões. Em uma circunstância como a nossa, é necessário meditar se vale mesmo a pena uma vida sem escolhas, responsabilidades, riscos, enfim, sem liberdade?

O terapeuta precisa, pois, alertar para os perigos do autoengano e desmascarar a ilusão da felicidade fácil. Na vida não há como fugir das dores, frustrações e decisões difíceis, que nos amadurecem e dão significado e singularidade existencial ao nosso viver. Ao contrário do que imagina uma geração superficial, efêmera, descomprometida com o sentido da vida, amoral e irresponsável, dedicar a vida a algo, fazer escolhas, investir em relações afetivas estáveis, não é caminho fácil, trilhado sem riscos ou sofrimentos. A psicoterapia não pode mistificar a realidade humana e perpetuar a infantilidade e a irrealidade. O psicoterapeuta tem o desafio ético de apostar na coragem para mudar, no fortalecimento íntimo para enfrentar as dificuldades inevitáveis, na inteligência para chegar a novas soluções, enfim, saídas éticas para as dificuldades próprias do viver. A existência humana é uma aventura povoada de riscos que a psicoterapia não vai eliminar, mas que precisa ajudar o homem a enfrentá-los melhor e sair deles fortalecido.

Gilberto Kujawski (1986) esclarece o que estamos dizendo do seguinte modo:

Viver é muito perigoso. Não porque a todo o momento surjam perigos na vida, mas porque a vida é em si mesma perigosa. Não que o perigo se acrescente ao viver, neste é que está o perigo (p. 3). 
Ele também menciona o que nos espera: "Hoje, o de que se trata, mais do que nunca, é de viver resolutamente. E não se entenda por isto a simulação de uma coragem que nem sempre seremos capazes de demonstrar. Viver resolutamente significa, apenas, viver resolvido a ser si mesmo" (idem, p. 5). Eis aí o que o terapeuta vai enfrentar, ele necessitará ajudar a pessoa a ser ela mesma, a não querer ser diferente do que é.

\section{V. Ética e procedimentos psicoterápicos}

O respeito ao homem como valor fundamental passa pelo modo como se empregam os métodos usados na Psicologia. Falar de método é referir-se ao modo de relação com o outro. Ensina Karl Jaspers que (1979): "o valor dos métodos se mede pelo que, com eles, posso ver, julgar e efetivar no trato com as pessoas" (p. 52). Portanto, o emprego de um procedimento só deve ser levado adiante no tanto que permita ajudar alguém. A psicoterapia não tem como ser aplicada sem se preservar a humanização do atendimento e o respeito que o cliente merece. Para realizar tal objetivo às vezes é necessário encaminhar o cliente a outro psicólogo que atua com maior nível de especialização, por exemplo, com crianças, com idosos ou com pacientes terminais. Outras vezes é necessário encaminhar a pessoa para outro profissional de saúde. Deixar de fazê-lo e, em qualquer dos casos, errando por imprudência ou imperícia, constitui uma grave falha ética.

O domínio de um procedimento é fundamental para o seu uso correto, mas o psicólogo tem uma dificuldade que outros profissionais normalmente não têm ou pelo menos não têm na mesma proporção, isto é, não lhe basta o domínio intelectual do procedimento a ser adotado. Mesmo que ele faça um diagnóstico exato, ainda que perceba rapidamente o que seu cliente vive, ele não pode expor o mundo interior do outro sem que este outro esteja preparado ou em condições de perceber o que lhe é revelado. Esta situação é mais evidente no tratamento das crianças, mas se aplica também aos adultos. Se este é o caso, é melhor que o terapeuta guarde para si o que descobriu. Bruno Bettelheim (1980) mostra

Educ. e Filos., Uberlândia, v. 20, n. 39, p. 131-146, jan./jun. 2006. 
que "é sempre invasor interpretar os pensamentos inconscientes de uma pessoa, tornar consciente o que ela deseja manter pré-

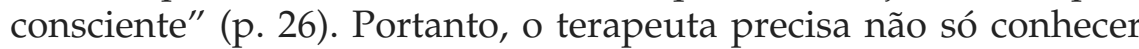
os procedimentos, mas saber o momento de empregá-lo. Isto é difícil, pois é muito estimulante aparecer para o cliente como quem sabe navegar pelo mundo alheio. No entanto, a habilidade do terapeuta está em que ele dê um passo de cada vez enquanto caminha pelo mundo do outro. Na relação entre o psicólogo e seu cliente, o primeiro invariavelmente aparece como mais poderoso, e a confiança entre eles ficará abalada se o cliente perceber que o terapeuta conhece o seu íntimo melhor do que ele próprio, que mergulha em seus sentimentos mais ocultos, identifica a verdadeira face de seus temores, antes que ele próprio se dê conta deles ou o autorize a fazê-lo. Ao buscar ajuda para seus problemas imediatos, a pessoa ordinariamente não sabe o que o terapeuta irá fazer para ajudá-la, será terrível se ficar apavorada ao descobrir um bisbilhoteiro da intimidade alheia.

O homem que procura auxílio não espera que o terapeuta o ajude? É claro que sim, mas ele deseja continuar a tocar sua vida, ele não abre mão de seguir um caminho próprio que assegure sua participação na sociedade e que preserve sua singularidade, tudo isto o mais próximo e coerente com os projetos e sonhos que acalenta.

Nós crescemos, encontramos sentido na vida e segurança em nós mesmos por termos entendido e resolvido problemas pessoais por nossa conta, e não por eles terem sido explicados por outros (idem, p. 27).

Não existem pessoas que precisam que as coisas lhes sejam ditas de forma racional e objetiva? É claro que sim, mas nem todos os existentes têm este propósito epistemológico tão desenvolvido. Mesmo quando o têm há um momento para ouvir as coisas que se passam neles, não antes que estejam disponíveis para entendê-lo e em condição de se confrontarem com seus tremores e dificuldades íntimas, dos quais, quase sempre, não estão conscientes. 
O existente quando busca ajuda não autoriza o terapeuta a vasculhar o seu mundo? Entendemos que sim. Mas quando ele percebe que o terapeuta chega tão fundo no seu íntimo, pode começar a temer o resultado desta relação. Está ele resistindo ao tratamento como costumam dizer os psicanalistas? Não parece ser o caso. Ninguém se sente à vontade para deixar o outro vasculhar sua intimidade sem antes sentir confiança, sintonia, amizade, enfim, uma certa harmonia com ele. Por este motivo, não se pode entrar no íntimo do outro sem licença e jeito, sem merecer a sua confiança. $\mathrm{O}$ cliente deve estar convencido de que o terapeuta não vai até seu íntimo para condená-lo, nem para descobrir inutilmente as razões últimas de sua existência, muito menos ainda para influir em suas convicções íntimas sobre questões relativas à organização do mundo ou sobre Deus. Ele confia que o psicoterapeuta só irá, até onde ele o permitir, se e no quanto for necessário para ajudá-lo. Ele descobrirá que também fará parte do mundo do terapeuta. A exceção é se ela perder as condições de estabelecer este limite, como ocorre, por exemplo, no caso de uma depressão profunda com tendências suicidas. Alguém profundamente deprimido experimenta, em alguns momentos, mudanças tão radicais que perde a possibilidade de avaliar a relação com o terapeuta. Perde a atividade normal do pensamento e a vontade de viver, fica em estado de torpor, apresenta inibição motora; diminui a consciência até graus profundos de estupor que se revela por uma imobilidade e detenção ou sentimento de redução do ritmo temporal. Nesta hora a sensibilidade do terapeuta lhe dirá o momento de agir, mas estes momentos são poucos em sua história profissional. O importante é acompanhar o ritmo do cliente, partilhar com respeito sua vida, estabelecer empatia com ele.

A empatia tem uma qualidade que nem sempre os terapeutas se dão conta, mas que distingue os exímios conhecedores da alma humana dos outros. Quando se vai ao mundo de alguém é inevitável que algo chegue também ao íntimo do visitante e mexa com ele. É melhor não simular ou fingir que assim ocorre. Não quer dizer que o terapeuta vá deixar de fazer o que precisa, nem que vá entrar nas fantasias ou no jogo do cliente, mas a qualidade da empatia

Educ. e Filos., Uberlândia, v. 20, n. 39, p. 131-146, jan./jun. 2006. 
pode ser melhor ou pior e isto conta no processo de ajuda.

O que isto significa? A relação psicoterapêutica coloca dois mundos em contato próximo. O terapeuta não ficará imune à relação com quem o procura, mesmo que não permita que a aproximação provoque um envolvimento negativo. Como observa Merleau-Ponty (1993), o psicoterapeuta precisa enfrentar "os procedimentos estabelecidos e que leve a transformar este condicionamento sofrido em condicionamento consciente, sem jamais negar a sua existência" (p. 22). Não se trata de julgar que o outro é igual a ele, ou que ele espera que seu cliente reaja como ele próprio o faria. A questão é de outra natureza. O terapeuta vai até o mundo do outro e ajudará a mudá-lo. É bom que ele esteja consciente de que o seu próprio mundo pode interferir nesta relação. Deve cuidar para diminuir as intervenções, mas não pode suprimi-la. Forghieri (1993) diz que o psicólogo precisa abandonar a atitude puramente intelectual "para se soltar ao fluir de sua própria vivência, nela penetrando de um modo espontâneo e profundo, para deixar surgir a intuição, percepção, sentimentos e sensações que brotam numa totalidade, proporcionando-lhe uma compreensão global, intuitiva e pré-reflexiva, dessa vivência" (p. 60).

Vamos falar um pouco mais da empatia sobre uma outra ótica que os psicólogos não estão familiarizados. Na filosofia clínica, que reúne um conjunto de procedimentos de ajuda pessoal, os aspectos da relação aparecem num capítulo denominado interseção, o processo depende da interpenetração dos mundos de quem ajuda e de quem partilha. A intercessão pode ser de muitos modos, conforme ensina Lúcio Packter (s.d.): "positiva, negativa, confusa ou indiferente" (p. 7). Como esta avaliação varia durante o processo, a questão é estimar se a relação afeta o uso do método que o terapeuta emprega, isto é difícil e tem implicações éticas. Se uma interseção é negativa, o que ocorre quando terapeuta e cliente sentem um mal-estar com a relação, e este sentimento persiste durante o processo psicoterápico, o mais adequado é encaminhar o cliente a outro profissional. No entanto, a relação pode ser também confusa, terapeuta e cliente não sabem o que estão vivenciando ou a relação oscila entre as formas anteriores. Nestes casos, o terapeuta 
deve estar preparado para enfrentar seus próprios limites. Não que ele desconheça os procedimentos nem que não tenha o domínio de seu mundo interior, é que a interseção não depende só dele. Esclarece Packter que pouco adianta o conhecimento "se a qualidade da interseção for ruim à atividade clínica" (p. 8). É o que queremos realçar quando tratamos a qualidade da relação entre o terapeuta e seu cliente.

Já dissemos que o psicoterapeuta precisa ter domínio do procedimento que emprega, superando dificuldades que venham a prejudicar a eficácia de sua intervenção, mas mostramos acima que o conhecimento só não basta. É esta a essência da questão, na relação terapêutica, a competência vai além do conhecimento teórico dos procedimentos a serem utilizados.

Vamos meditar um pouco mais sobre esta questão. A relação psicoterápica tem repercussões éticas e envolve o problema do valor. As discussões teóricas e o rigor conceitual têm importância didática, mas não são imprescindíveis quando se está diante do outro, esclarece Jaspers (1979):

Discussões metodológicas só têm sentido quando se realizam sobre um material concreto e ao mesmo tempo se explicam em suas conseqüências. Abstrações metodológicas destituídas de experiência são enfadonhas. Nas ciências empíricas só vale a lógica concreta. Puras argumentações, sem investigações de fatos ou exposições de material, pairam soltas no ar. Excogitar métodos, que são ou talvez até nem possam ser aplicados, só produz falatórios metodológicos sem conteúdo (p. 53).

As considerações de Jaspers não desvalorizam o conhecimento teórico. Sem estudos profundos dos procedimentos que irá utilizar, o terapeuta acaba sem proceder distinções essenciais dos transtornos psicológicos, muitas vezes representando, de forma, pior ou descontextualizada, conhecimentos bem sabidos e organizados. A questão é, pois, de natureza ética, o psicoterapeuta precisa aprender a colocar como primeiro objetivo da clínica a pessoa humana, ou melhor, o respeito a um mundo singular com

Educ. e Filos., Uberlândia, v. 20, n. 39, p. 131-146, jan./jun. 2006. 
projetos e liberdade de executá-lo. Ajudá-la, o melhor possível, quando suas funções intelectuais, volitivas ou emocionais estiverem comprometidas, prejudicando viver o sentido da sua vida. O sentido da vida é continuamente revisto por todos nós ao longo da nossa história. Algumas coisas foram importantes num certo tempo, mas podem deixar de sê-lo. Outras serão sempre fundamentais em nossa existência.

Há, ainda, um problema complicado a ser considerado. O sistema de saúde e as empresas de saúde privadas não cobrem as despesas com psicólogo. A terapia precisa permitir ao cliente honrar seus compromissos e, simultaneamente, assegurar a justa remuneração do trabalho do psicólogo, sem o que o tratamento acaba tendo seus aspectos básicos comprometidos. Esta é questão difícil porque o tratamento psicoterápico é caro, os seguros de saúde não o cobrem e a população brasileira é pobre.

\section{Considerações finais}

Pudemos mostrar neste trabalho que, no processo psicoterápico, as relações entre quem ajuda e quem é ajudado não são marcadas pela absoluta falta de limite e também que as influências estabelecidas são mútuas. Mostramos também que é importante assegurar a aplicação correta dos procedimentos clínicos já validados, mas explicamos que isto não eqüivale a ausência de limites. Conforme observa Pegoraro (2001): “A ciência existe para descobrir a natureza e promover a vida, a saúde e a liberdade das pessoas e da sociedade" (p. 60). O psicoterapeuta lida com o íntimo das pessoas e deve saber como e até onde ir. Precisa estar preparado para os tipos de intercessão que vai estabelecer, mudando-as para melhor.

As ciências humanas lidam com um objeto que se distingue dos outros porque muda fundamentalmente sua condição de existência como parte de seu existir. Os procedimentos clínicos e, em especial, os que têm função psicoterápica, não podem desconhecer que o homem é livre e que ele escolhe seu destino em função de valores adequados a seu modo de viver. O homem possui 
igualmente uma dimensão natural que pode ser tratada com procedimentos bem construídos e testados, mas ele não é só natureza. A fenomenologia revelou que o homem tem, além do aspecto natural, corpo e alma psicológica, um espírito que lhe permite agir e criar com liberdade. Ao valer-se desta circunstância, o homem criou um código de valores éticos que, aos poucos, ganhou reconhecimento objetivo. Dos valores morais, o mais importante é ele próprio, o valor central da cultura que cria, o valor fonte do qual todos os outros provêm. A relação psicoterápica não foge de ser um encontro entre pessoas livres e diferentes, em que a simpatia e o respeito profundo devem ser os guias do encontro.

Concluímos, então, que não são os psicólogos, conhecedores que são do comportamento humano, que irão estabelecer os valores da relação de ajuda. Os valores que guiam os procedimentos psicote-rápicos são estabelecidos pela sociedade, cada geração o faz com base nas informações disponíveis e desafios que têm que enfrentar.

\section{Bibliografia}

BETTELHEIM, Bruno. A psicanálise dos contos de fada. 10. reimp. Rio de Janeiro: Paz e Terra, 1980.

CARVALHO, José Mauricio de. O homem e a filosofia. Porto Alegre: EDIPUCRS, 1998.

Introdução à filosofia da razão vital. Londrina: Cefil, 2002.

Problemas e teorias da ética contemporânea. Porto Alegre: EDIPUCRS, 2004.

CUNHA, Jurema Alcides. Dicionário dos termos de psicanálise de Freud. Porto Alegre: Globo, 1978.

EY, Henri; BERNARD, P.; BRISSET, Ch. Tratado de psiquiatría. 8. ed. Barcelona: Masson, 1978.

Educ. e Filos., Uberlândia, v. 20, n. 39, p. 131-146, jan./jun. 2006. 
ESPINOLA, M. C. de Oliveira. Albert Camus; para uma ética da solidariedade. Londrina: EDUEL, 1998.

FORGHIERI, Yolanda Cintrão. Psicologia fenomenológica. São Paulo: Pioneira, 1993.

GARAUDY, Roger. Perspectivas do homem. Rio de Janeiro: Civilização Brasileira, 1966.

JASPERS, Karl. Psicopatologia geral. Rio de Janeiro: Atheneu: 1979.

KUJAWSKI, Gilberto de Mello. Viver é perigoso. 2. ed. São Paulo: GDR, 1986.

LEMOS, Inêz. Fé em tempo de consumo. Estado de Minas. Caderno Pensar. 13 dez. 2003.

Eros na alma humana. Estado de Minas. Caderno Pensar. 21 fev. 2004.

MERLEAU-PONTY, Maurice. Ciências do homem e fenomenologia. São Paulo: Saraiva, 1993.

PACKTER, Lúcio. Cadernos de Filosofia Clínica. Porto Alegre: Instituto Packter, s. d.

PAIM, Antônio. Tratado de ética. Londrina: Humanidades, 2003.

PEGORARO, Olinto. Ética e ciência. In: Vários. Ética, ciência e saúde. Petrópolis: Vozes, 2002.

PIERON, Henri. Dicionário de Psicologia. 2. ed. Porto Alegre: Globo, 1975.

REALE, Miguel. Verdade e conjectura. Rio de Janeiro: Nova Fronteira, 1987. 
Introdução à filosofia. 2. ed. São Paulo: Saraiva, 1989.

SOUZA, Artur Custódio Moreira de. Ética e informação para o usuário. In: Vários. Ética, ciência e saúde. Petrópolis: Vozes, 2002.

Data de Registro 11/05/05

Data de Aceite 28/06/05 